\title{
A HOSPITAL-WITHIN-A-HOSPITAL: GOOD FoR HOSPITALS, GOOD FoR PATIENTS
}

\author{
Patricia Connelly*
}

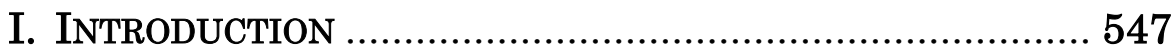

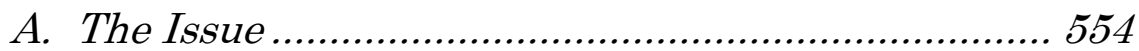

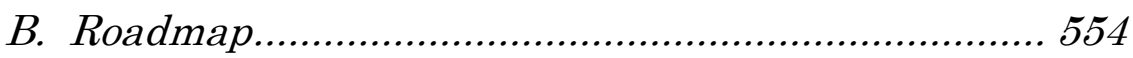

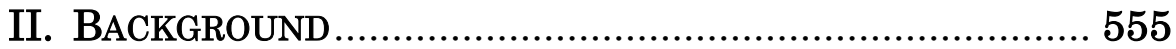

A. Medicare Reimbursement for Hospitals ${ }^{-}$................ 555

Within-Hospitals ................................................ 555

B. Hospital-Within-a-Hospital Design and Operation. 557

1. Separateness Requirement: Basic Functions ....... 560

2. Separateness Requirement: Contracts with HospitalWithin-A-Hospital No More Than Fifteen Percent of Host's Total Inpatient Operating Costs ................... 561 3. Separateness Requirement: Inpatient Population Referral............................................................... 563

C. Alternatives to Hospitals-Within-Hospitals ........... 563

III. ADVANTAGES OF HOSPITALS-WITHIN-HOSPITALS......... 565

A. A Hospital-Within-A-Hospital Increases ............... 565 Physician Empowerment ................................... 565

B. Reduction in Readmission Rates........................... 569

C. Specialty Hospitals Expand Access to Care............ 572

D. A Unique Model of "Separateness" ........................ 574

IV. PROBLEMS ASSOCIATED WITH A HOSPITAL-

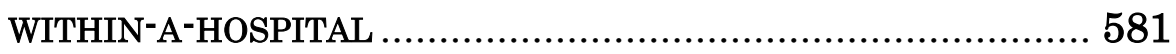

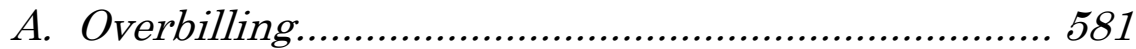

B. "Separateness" as an Impediment to ..................... 584

Disaster Preparedness ...................................... 584

V. CoNCLUSION …….................................................. 592

* J.D. Candidate, 2016, Indiana University-Robert H. McKinney School of Law; B.S., 2011, Oklahoma State Universiy. 


\section{INTRODUCTION}

Hospitals face constant pressure to achieve both financial health and their mission of promoting health and wellness within the communities they serve. The ever-changing regulatory landscape of the health care industry forces hospitals to constantly adapt to new methods of treating patients while meeting specific quality measures and managing their budgets. Hospitals are complex organizations and keeping them afloat operationally is a difficult task, fraught with financial penalties and bad publicity for any missteps. Credit rating agencies are forecasting a negative outlook for non-profit healthcare due to credit ratings downgrades, decreases in cash, and the uncertainty that the newly elected 2015 Republican-led Congress will make changes to the Patient Protection and Affordable Care Act, also known as the Affordable Care Act ("ACA") or "Obamacare."1

As hospitals adjust to the new regulatory requirements of the Affordable Care Act, like value-based purchasing, more penalties for hospital acquired conditions, and the

${ }^{1}$ Robin Respaut, Grim Outlook for Healthcare, Hospital Sector in 2015: Rating Agencies, REUTERS (Dec. 16, 2014, 7:08 PM), http://www.reuters.com/article/2014/12/17/us-healthcare-nonprofitratings-idUSKBN0JV00R20141217 [http://perma.cc/LY5C-YZNY]. Under a Republican majority, the House of Representatives has held more than 50 votes to either repeal or defund parts of the ACA or the entire ACA since it became law in 2010. House GOP to Hold First ObamaCare Repeal Vote of New Congress, Fox News (Jan. 27, 2015), http://www.foxnews.com/ politics/2015/01/27/house-gop-to-hold-firstobamacare-repeal-vote-new-congress/ [http://perma.cc/357Q-ZS5M]. 
readmissions reduction program, they are forced to make adjustments.

Value-based-purchasing is an incentive system that will change the amount hospitals are paid based on their performance. Payments to hospitals will be adjusted based "on their performance on 4 domains that reflect hospital quality: the clinical process of care domain, the patient experience of care domain, the outcome domain, and the efficiency domain." 2 The ACA mandates "a hospital valuebased purchasing program in Medicare to pay hospitals based on performance on quality measures." ${ }^{3}$ Fee-for-service models of reimbursement, where hospitals charge for each service performed on the patient as opposed to overall outcome, are being supplanted by value-based care. Valuebased care is a growing trend among the biggest insurance companies, because insurance companies tend to follow Medicare and Medicaid trends. ${ }^{4}$ A shift toward

value-based reimbursements has been a major driver of healthcare reform, and United Healthcare is not the only commercial payer to signal a major shift toward this strategy. Aetna and Cigna have been two of the most active private health insurers to create ACOs and

2 Hospital Value-Based Purchasing, MEDICARE.GOV, http:// www.medicare.gov/hospitalcompare/Data/hospital-vbp.html [http:// perma.cc/A9K8-HCFC] (last visited Feb. 12, 2016).

${ }^{3}$ Summary of the Affordable Care Act, The KaISER FAM. Found. (Apr. 25, 2015), http://kff.org/health-reform/fact-sheet/summary-of-theaffordable-care-act/ [http://perma.cc/5NNP-WCKV].

${ }^{4}$ Bob Herman, United HealthCare to Double Value-Based Contracts with Providers by 2017, BECKER's HosP. ReV. (July 10, 2013), http://www.beckershospitalreview.com/accountable-care-organizations/ unitedhealthcare-to-double-value-based-contracts-with-providers-by2017.html [http://perma.cc/ZK4N-WJYH]. 
accountable care deals with hospitals and physicians. $^{5}$

Seeking to reduce inefficiencies in care is important to insurers as well. ${ }^{6}$ Value-based care will pressure hospitals and health care providers to shift resources toward improving areas measured by these metrics.

Beginning in October of 2008, hospitals had to supply information about conditions present on admission ("POA") and did not "receive additional payment for cases in which one of the selected conditions was not present on admission. That is, the case would be paid as though the secondary diagnosis were not present." 7 Basically, the policy is based

5 Id.

6 Bruce Japsen, Blue Cross' \$65 Billion Move Away From Fee-ForService Medicine, FORBES (July 9, 2014, 11:00 AM), http:// www.forbes.com/sites/brucejapsen/2014/07/09/blue-cross-65-billionmove-away-from-fee-for-service-medicine/ [http://perma.cc/XDK5-47TW].

7 Hospital-Acquired Conditions (Present on Admission Indicator), CMS.Gov, http://www.cms.gov/Medicare/Medicare-Fee-for-ServicePayment/HospitalAcqCond/index.html?redirect=/hospitalacqcond/06_ho spital-acquired_conditions.asp [http://perma.cc/9ATZ-9HU2] (last visited Feb. 28, 2016). The details of this program are as follows:

On February 8, 2006, the President signed the Deficit Reduction Act (DRA) of 2005. Section 5001(c) of DRA requires the Secretary to identify conditions that are: (a) high cost or high volume or both, (b) result in the assignment of a case to a DRG that has a higher payment when present as a secondary diagnosis, and (c) could reasonably have been prevented through the application of evidence-based guidelines. Section 5001(c) provides that CMS can revise the list of conditions from time to time, as long as it contains at least two conditions. Id. 
on the idea that the government should not reward hospitals for treating patients for conditions that a patient contracted while at the hospital that could have potentially been avoided by better hospital practices.

This payment structure encouraged hospitals to take measures to combat Hospital-Acquired Conditions ("HACs"). Additional penalties for Hospital-Acquired Conditions ("HACs") were implemented by Obamacare. ${ }^{8}$ This program will result in reduced Medicare payments to hospitals that do not meet quality metrics involving hospital acquired conditions. A score is created for hospitals based on

rank in the worst performing quartile ... with respect to hospital-acquired conditions . . . . identified by calculating a Total HAC score which is based on the hospital's performance on risk adjusted quality measures. Hospitals with a Total HAC score above the 75th percentile of the Total HAC Score distribution may be subject to payment reduction beginning October $1,2014 .^{9}$

Hospitals must make investments to develop or refine internal processes that prevent patients from acquiring additional illnesses during their stay.

Established by the Affordable Care Act, the Readmissions Reduction Program also imposes penalties on hospitals. ${ }^{10}$ The Secretary of the Health and Human Services agency

${ }^{8}$ Hospital-Acquired Condition Reduction Program, MedicARe Hosp. COMPARE, http://www.medicare.gov/hospitalcompare/HAC-reductionprogram.html [http://perma.cc/T6WE-6Q35] (last visited Mar. 12, 2015).

9 Linking Quality to Payment, MEDICARE HosP. COMPARE, http://www.medicare.gov/hospitalcompare/linking-quality-topayment.html?AspxAutoDetectCookieSupport=1 [http://perma.cc/3EGDCAWK] (last visited Feb. 28, 2016).

$10 I d$. 
("HHS") is charged with taking excess readmissions into consideration when making payments to hospitals. ${ }^{11}$ In addition to financial penalties, the readmissions rates will also be posted on the CMS website "Hospital Compare."12 This will impact hospitals as consumers will have the opportunity to research prices for different procedures before selecting a hospital or outpatient clinic.

Carrots and sticks like value-based purchasing, the Readmissions Reductions program, and HAC program are "the wave of the future for hospital payments and should be viewed as a cumulative force demanding performance improvement[.]"13 Additionally, "[b]y 2017, the combined penalties will put as much as $6 \%$ of inpatient Medicare reimbursements at risk." 14 This will put pressure on hospitals to react to this new status quo.

In March of 2015, the Supreme Court heard oral arguments on King v. Burwell, where it was argued that the subsidies from the federal government for people who purchased health insurance from the federal health insurance exchange were illegal, based on the interpretation of an IRS rule. ${ }^{15}$ The outcome of King V. Burwell was to have an impact on whether individuals, in states that only use the federal health insurance exchange market,

1142 U.S.C. $\S 1395 \mathrm{ww}(\mathrm{q})(2016)$.

1242 U.S.C. § 1395ww(q)(8)(B) (2016).

13 Sabriya Rice et al., More Hospitals to Get Bonuses Than Penalties in 2015 Under Value-Based Purchasing, Modern HEalthCARE (Dec. 18, 2014), http://www.modernhealthcare.com/article/20141218/NEWS/ 141219982 [http://perma.cc/FM58-28T9].

${ }^{14} \mathrm{Id}$.

15 King v. Burwell, 135 S. Ct. 2480, 2482 (2015). 
HealthCare.gov, ${ }^{16}$ would receive subsidies to help them afford health insurance. ${ }^{17}$ Thirty-four states relied on the federal exchange for their insurance market, and roughly six and a half million people stood to lose their subsidies if the Supreme Court found that the federal health insurance exchange markets were illegal. ${ }^{18}$ Without the subsidies, less patients would have insurance, and the amount of uninsured patients would likely increase.

Subsidies have made an impact on hospital debt because they result in less uninsured patients whose costs hospitals have to absorb. ${ }^{19}$ In 2015, there was an increase in the number of Indiana residents who enrolled through the federal marketplace. ${ }^{20}$ Enrollment for Hoosiers was 132,423 in 2014, and in 2015 it increased to 218,617. ${ }^{21}$ The increased number of insured patients has resulted in a surge in patient volume, but hospitals are struggling with the costs of increasing staff to handle the patient volume. ${ }^{22}$ The uncertainty around the King decision made it difficult for hospitals to operate efficiently while they evaluated whether or not they should maintain staff at current levels and proceed as if the number of insured patients will continue to increase or if they need to reduce staff if the pool of insured patients decreases if subsidies are not preserved. Although

16 HEALTHCARE.GOV, http://www.healthcare.gov/ [http://perma.cc/ GV8C-UEDT68H4-JNJ3] (last visited Feb. 12, 2016).

17 King v. Burwell, 135 S. Ct. 2480, 2482 (2015).

18 The Health Care Supreme Court Case: Who Would Be Affected? N.Y. TIMES, http://nytimes.com/interactive/2015/03/03/us/potentialimpact-of-the-supreme-courts-decision-on-health-care-

subsidies.html?_r=0 [http://perma.cc/82CE-2KJU] (last updated June 22, 2015).

${ }^{19}$ Caroline Humer \& Bill Berkrot, U.S. Hospitals Optimistic They'll Dodge Bullet With Obamacare Ruling, Reuters (Mar. 4, 2015, 6:16 PM), http://www.reuters.com/article/2015/03/04/us-usa-court-healthcarehospitals-idUSKBN0M02NC20150304 [http://perma.cc/3PU9-C9SR].

${ }^{20}$ Barbara Brosher, More Hoosiers Enroll in Healthcare Coverage for 2015, IND. PUB. MEDIA (Feb. 18, 2015), http:// indianapublicmedia.org/ news/hoosiers-enroll-healthcare-coverage-2015-78383/ [http://perma.cc/ 95DG-ELDG].

${ }^{21} I d$.

22 Beth Kutscher, Reform Update: Hospitals See More Paying Patients, but There's a Hitch, Modern HealthCARe (Aug. 20, 2014), http://www.modernhealthcare.com/article/20140820/NEWS/308209965 [http://perma.cc/WA5A-8SKK]. 
the outcome of King maintained the subsidies, hospitals will continue to face great uncertainty as different aspects of the ACA are attacked and reviewed, especially during the upcoming presidential election.

The competition among hospitals and the internal pressures within hospitals is fierce. Pressure to gain new patients, maintain prowess in the community, achieve financial stability, and provide the best care possible to all patients is intense. As a result of this increasing competitive pressure, it is not uncommon for the public to frequently encounter commercials and billboards advertising shorter wait times in emergency rooms, new specialty centers, and a facility's latest ranking of varying significance. The inundation of advertisements gives the prospective patient the impression that the hospitals are all trying to shout over one another in an effort to attract the patient's attention and business.

As more people are covered by high-deductible insurance plans, where patients must pay a greater amount out of pocket before their health care costs are covered by their insurance, there is a general sense that patients are interested in greater price transparency. The Indiana Hospital Association created a tool called CareINSight for patients to view aggregated hospital price and quality data for the more than 165 hospitals in Indiana based on the chargemasters hospitals submit to the Indiana State Department of Insurance. ${ }^{23}$ While this tool is not a perfect

${ }^{23}$ J.K. Wall, Hoosier Hospitals Create New Tool to Help Health Care Shoppers, IND. BUS. J. (Jan. 5, 2015), http://www.ibj.com/blogs/12-thedose/post/51173-hoosier-hospitals-create-new-tool-to-help-health-careshoppers?utm_source=ibj- 
way to view all relevant data because it does not include information from all of the different payers who will pay for hospital procedures, the number of all-payer claims databases is likely to grow. ${ }^{24}$ All-payer claims databases will put pressure on hospitals to incur additional administrative costs in order to maintain this information.

There are many pressures on hospitals to be more efficient without sacrificing quality. These challenges present an opportunity for hospitals to create new structures to adjust to this pressure while managing patient satisfaction, quality, and their bottom line.

\section{A. The Issue}

As discussed above, the health industry is facing many new regulatory changes that present operational and financial challenges. Colocation via the hospital-within-ahospital structure could relieve some of the pressures hospitals must navigate. The unique structure of a hospitalwithin-a-hospital provides a means for hospitals to gain financial efficiencies, and improve patient care-by reducing readmission rates by ensuring patients receive better care, and providing a means for Catholic hospitals that acquire secular hospitals to address the needs of the communities they serve while adhering to their moral objectives.

\section{B. Roadmap}

This Note will examine the "hospital-within-a-hospital" structure under the general rules for hospitals excluded from the prospective payment systems ${ }^{25}$ and analyze the advantages and disadvantages of this structure for hospitals and patients. Also analyzed is how the hospital-within-ahospital structure provides a means to ease the impact of

daily\&utm_medium=newsletter\&utm_content=the-

dose\&utm_campaign=2015-01-06 [http://perma.cc/3WNX-WQS2].

24 Id; See also APCD Council, The Basics of All-Payer Claims Databases: A Primer for States, RoBert WoOD JoHnson Found. (Jan. 2014), http://www.rwjf.org/content/dam/farm/reports/issue_briefs/2014/ rwjf409988 [http://perma.cc/39AF-N7XX].

2542 C.F.R. $\S 412.22$ (2016). 
regulatory uncertainty on hospitals and how the type of hospitals, currently allowed to operate hospitals-withinhospitals, should be expanded to include hospitals other than specialty hospitals.

Part II of this Note will discuss the Medicare reimbursement for a hospital-within-a-hospital, the design and operation of the hospital-within-a-hospital, the requirements hospitals must adhere to in order to be compliant with the regulation and therefore receive the appropriate type of Medicare reimbursement, and alternatives to hospitals-within-hospitals.

Part III of this Note will analyze-the advantages of the hospital-within-a-hospital including: potential reduction in readmission rates for the host hospital which in turn benefits the patients as consumers of health care, an increase in access to specialty hospitals, and how the separateness of the structure could increase access to certain services.

Explored in Part IV of this Note are the disadvantages of the hospital-within-a-hospital, including overbilling, which leads to Medicare overpayment, and complications that arise when disaster preparedness is inadequate between the hospital-within-a-hospital and the host hospital.

\section{BACKGROUND}

\section{A. Medicare Reimbursement for Hospitals- Within-Hospitals}

Even though participation is voluntary, hospitals choose to participate in the Medicare program for a variety of 
reasons, such as tax exemptions. ${ }^{26}$ Health care providers who want to accept Medicare payments must abide by CMS regulations. Medicare is a health insurance program run by the Centers for Medicare and Medicaid Services ("CMS"), as the operating agent of the Department of Health and Human Services ("HHS"), meant to assist both the elderly and the disabled. ${ }^{27}$ Hospitals agree to provide hospital services to those eligible for Medicare when hospitals file their agreement with the Secretary of HHS. ${ }^{28}$ Acute care hospitals agree to accept Inpatient Prospective Payment System ("IPPS") payments when they deliver inpatient care to Medicare patients. ${ }^{29}$ Medicare pays for acute care hospital operating costs under a system called the prospective payment system ("Inpatient PPS"), where each discharge is paid for according to a predetermined specific rate. ${ }^{30}$ The prospective payment system was established for:

the operating costs of inpatient hospital services furnished to Medicare beneficiaries in cost reporting periods beginning on or after October 1, 1983 and a prospective payment system for the capital-related costs of inpatient hospital services furnished to Medicare beneficiaries in

${ }_{26}$ Underpayment by Medicare and Medicaid Fact Sheet, AM. HosP. Ass'N, 1 (Nov. 2009), www.aha.org/content/00100010001000-100010/ 09medicunderpayment.pdf [http://perma.cc/5RFM-DN3R].

27 Select Specialty Hosp. Akron, LLC v. Sebelius, 820 F. Supp. 2d 13, 15-16 (D.D.C. 2011).

2842 U.S.C. $\$ 1395 \mathrm{cc}$ (2016).

${ }^{29}$ Dept. of Health and Human Svcs. Ctrs. for Medicare \& Medicaid Svcs., Acute Care Hospital Inpatient Prospective Payment System (Apr. 2013), http://www.cms.gov/Outreach-and-Education/Medicare-LearningNetwork-MLN/MLNProducts/downloads/AcutePaymtSysfctsht.pdf [http://perma.cc/Y2PN-35XV]. .

30 See Select Specialty Hosp., 820 F. Supp. 2d at 17. 
cost reporting periods beginning on or after October 1, 1991. ${ }^{31}$

Payments made to participating hospitals are made on the basis of prospectively determined rates and applied on a per discharge basis. ${ }^{32}$ The payment system is not structured in a way to reimburse hospitals for long-term hospital care because the average stay for Medicare patients at general acute-care hospitals is roughly six days. ${ }^{33}$ A hospital-withina-hospital is excluded from this payment system. Instead, they are compensated at a level that is often more favorable.

\section{B. Hospital-Within-a-Hospital Design and Operation}

Under 42 C.F.R. § 412.22(e), "Excluded hospitals and hospital units: General rules", a hospital-within-a-hospital is a hospital that operates in the same building as its host hospital or in a building on the same campus as its host hospital. ${ }^{34}$ This is sometimes referred to as co-location. ${ }^{35}$ The host hospital is "a general acute care hospital located in the same building or on the same campus as [a long-term-care-

3142 C.F.R. $\S 412.1$ (a) (2016).

$32 I d$.

${ }^{33}$ See Select Specialty Hosp., 820 F. Supp. $2 \mathrm{~d}$ at 17.

3442 C.F.R. § 412.22(e) (2016).

35 Cherilyn G. Murer, Separate But Related-Hospitals Within Hospitals and the 15 Percent Inpatient Operating Costs Limitations 1, available at http://murer.com/pdfs/articles/thecolocationequation.pdf [http://perma.cc/6295-Z3SH]. 
hospital]." 36 Colocation is typically arranged through a lease arrangement. ${ }^{37}$

Facilities that meet the requirements for a hospitalwithin-a-hospital are excluded from this Medicare Inpatient prospective payment system. ${ }^{38}$ In order to be the type of facility allowed to become a hospital-within-a-hospital, the facility must be licensed as of the several classes of "excluded hospitals." 39 These facilities include:

1. Psychiatric hospitals, which must primarily provide psychiatric care, including the diagnosis and treatment of the mentally ill, ${ }^{40}$

2. Rehabilitation hospitals, which must comport with specific requirements, ${ }^{41}$

3. Children's hospitals, which must have a provider agreement and provide care to patients under eighteen years of age, ${ }^{42}$ and

4. Long-term care hospitals ("LTCH"), which are one of the types of specialty hospitals permitted to operate as hospitals-within-hospitals, must have an average length of stay that is greater than twenty-five days. ${ }^{43}$ Because of concerns involving overbilling Medicare, a moratorium on all new long-term care hospitals has been established. ${ }^{4}$

In part, due to concerns about hospitals working together to double bill Medicare for the same patient, there are requirements in place for a host hospital and hospital-withina-hospital to qualify for reimbursement under 42 C.F.R. $\S$ $412.22(\mathrm{e})$. Maintaining separateness is at the root of the

\footnotetext{
36 Select Specialty Hosp., 820 F. Supp. 2d at 17.

37 Murer, supra note 35 , at 1.

3842 C.F.R. § 412.22(e) (2016).

3942 C.F.R. $\S 412.22$ (a) (2016).

4042 C.F.R. § 412.23(a) (2016).

4142 C.F.R. $\S 412.29$ (2016).

4242 C.F.R. § 412.23(d) (2016).

4342 C.F.R. $\S 412.23(\mathrm{e})(2016)$.

4442 C.F.R. § 412.23(e)(6) (2016).
} 
requirements for fulfilling the criteria to qualify as a hospital-within-a-hospital. The operations of both the host hospital and the hospital-within-a-hospital are structured in a way to prevent collusion between the host hospital and the hospital-within-a-hospital.

This separateness is often signified in terms of control. Control is defined as having "the power, directly or indirectly, significantly to influence or direct the actions or policies of an organization or institution." 45 The governing body of the hospital-within-a-hospital must be separate from the governing body of the host hospital. ${ }^{46}$ The chief medical officer of the host hospital, who is responsible for the actions of the medical staff, may not be employed by or have a contract with the hospital-within-a-hospital. ${ }^{47}$ The medical staff must also be separate. This means that the host hospital's medical staff has nothing to do with the hospitalwithin-a-hospital's staffing activities, including granting privileges. ${ }^{48}$ The chief executive officer of the host hospital may not be "employed by or under contract with the hospital occupying space in the same building or on the same campus or any third entity that controls both hospitals." 49

However, in addition to requirements on separate governance and staffing the hospital-within-a-hospital also has to meet one of the three criteria explored in further detail below to establish the separateness of the two hospitals and qualify as a hospital-within-a-hospital:

\footnotetext{
4542 C.F.R. $\S 412.22$ (g) (2016).

4642 C.F.R. $\S 412.22(\mathrm{e})(1)(\mathrm{i})(2016)$.

4742 C.F.R. $\S 412.22(\mathrm{e})(1)(\mathrm{ii})(2016)$.

4842 C.F.R. $\S 412.22(\mathrm{e})(1)(\mathrm{iii})(2016)$.

4942 C.F.R. $\$ 412.22$ (e)(1)(iv) (2016).
} 
1. Perform "basic functions" without contracting with the host hospital to provide these services, ${ }^{50}$

2. No more than fifteen percent of the host hospitals' inpatient operating costs may come from contracts with the hospital-within-a-hospital, ${ }^{51}$ or

3. Seventy-five percent of the hospital-within-a-hospital's inpatient population must be referred from somewhere besides the host hospital. ${ }^{52}$

\section{Separateness Requirement: Basic Functions}

As the first option to establish separateness between the host hospital and the hospital-within-a-hospital, the hospital-within-a-hospital must perform basic hospital functions "through the use of employees or under contracts or other agreements with entities other than the hospital occupying space in the same building or on the same campus, or a third entity that controls both hospitals." 53 Basic functions are defined as: "quality assurance, medical staff services, nursing services, medical record services, pharmaceutical services, radiologic services, laboratory services, utilization review, and infection control." ${ }^{54}$ It is permissible for the hospital-within-a-hospital to contract with the host hospital or any third party that controls both hospitals to provide "food and dietetic services and housekeeping, maintenance, and other services necessary to maintain a clean and safe physical environment." 55

One of the issues with this rule is that the host hospital could provide basic functions in the most cost-effective

\footnotetext{
5042 C.F.R. $\S 412.22(\mathrm{e})(1)(\mathrm{v})(\mathrm{A})(2016)$.

5142 C.F.R. $\S 412.22(\mathrm{e})(1)(\mathrm{v})(\mathrm{B})(2016)$.

5242 C.F.R. $\S 412.22(\mathrm{e})(1)(\mathrm{v})(\mathrm{C})(2016)$.

5342 C.F.R. $\S 412.22$ (e)(1)(v)(A) (2016).

${ }^{54}$ Murer, supra note 35 , at 2.

5542 C.F.R. § 412.22(e)(1)(v)(A) (2016).
} 
manner for the hospital-within-a-hospital.56 A hospitalwithin-a-hospital that is, for example, only comprised of twenty beds would not see operational efficiencies if it were forced to procure costly assets like radiological or laboratory equipment. 57 Additionally, it would inconvenience patients and increase costs if the hospital-within-a-hospital needed to call an ambulance any time a patient needed a test that the hospital-within-a-hospital was not equipped to perform and is then obligated to arrange and pay for an ambulance to transport the patient to a facility that did have the equipment. 58

This option is still available. However, in response to the concerns about the lack of convenience and cost effectiveness of the basic services rule, CMS added two alternatives that a hospital-within-a-hospital could choose to fulfill the idea of separate function while easing the burden of the original rule. ${ }^{59}$

2. Separateness Requirement: Contracts with HospitalWithin-A-Hospital No More Than Fifteen Percent of Host's Total Inpatient Operating Costs

As another option to establish separateness between the host hospital and the hospital-within-a-hospital, the hospital can ensure that

\footnotetext{
${ }^{56}$ Murer, supra note 35, at 2.

${ }^{57} \mathrm{Id}$.

${ }_{58} I d$.

${ }^{59} I d$.
} 
the cost of the services that the hospital obtains under contracts or other agreements with the hospital occupying space in the same building or on the same campus, or with a third entity that controls both hospitals, is no more than 15 percent of the hospital's total inpatient operating costs ....60

The fifteen percent of total inpatient operating costs cap on services rule has been described as the most confusing rule for hospitals-within-hospitals because of the difficulty in accounting for which services count towards the fifteen percent. ${ }^{61}$ However, most hospitals choose to abide by this rule. 62 Inpatient operating costs include costs for routine services, like the cost of the room and board and nursing, ancillary services including inpatient radiology and laboratory services, and the malpractice insurance costs associated with inpatient care. ${ }^{63}$ Costs that must be included in the fifteen percent maximum a hospital-within-a-hospital may contract with the host for includes equipment and facility repairs and maintenance, cleaning, utilities, and general liability insurance. ${ }^{64}$ The hospital-within-a-hospital may not contract with the host hospital or an entity that controls the host hospital for pharmacy, nursing services or medical records. ${ }^{65}$ However, the hospital-within-a-hospital is permitted to attempt to realize cost efficiencies by contracting with the host hospital for "dietetic, housekeeping, and maintenance services."66

\footnotetext{
6042 C.F.R. $\S 412.22(\mathrm{e})(1)(\mathrm{v})(\mathrm{B})(2016)$.

${ }_{61}$ Murer, supra note 35, at 1.

${ }^{62} \mathrm{Id}$.

6342 C.F.R. $\S 412.2$ (c) (2016).

${ }^{64}$ Murer, supra note 35, at 4.

${ }^{65} \mathrm{Id}$.

${ }_{66} I d$.
} 


\section{Separateness Requirement: Inpatient Population Referral}

If a hospital chooses to adhere by the " $75 \%$ Rule," no more than twenty-five percent of the inpatient population of the hospital-within-a-hospital can be referred by the host hospital.67 This means that seventy-five percent of the referrals to the hospitals must come from a source other than the host hospital.68 If a hospital-within-a-hospital chooses this option as the means to establish separateness from the host hospital, it will deny itself the opportunity to form a mutually beneficial relationship with the host hospital because most hospitals-within-hospitals "receive the bulk of their referrals from the host hospital." 69

\section{Alternatives to Hospitals-Within-Hospitals}

It is important to note that the term "hospital-within-ahospital" is used to refer generally to any arrangement that has multiple hospitals in the same physical location, but that does not mean that the facility is a true "hospital-within-ahospital" under the statute. Some hospitals market specialty floors as "hospitals-within-hospitals" when in fact they are just remote locations or satellite facilities, subject to other requirements. A satellite facility is a part of a hospital that provides inpatient services in a building also used by another hospital. 70 Satellite facilities are also restricted to "hosting"

6742 C.F.R. $\S 412.22(\mathrm{e})(1)(\mathrm{v})(\mathrm{C})(2016)$.

$68 \mathrm{Id}$.

${ }^{69}$ Murer, supra note 35, at 3.

70 Select Specialty Hosp., 820 F. Supp. 2d at 17. 
only psychiatric, rehabilitation, children's, and long-term care hospitals. ${ }^{71}$ Satellite facilities are also similar to hospitals-within-hospitals because they may not be controlled by the same board or CEO as the host hospital, "and it furnishes inpatient care through the use of medical personnel who are not under the control of the medical staff or chief medical officer of the hospital in which it is located."72

Hospitals are accredited by surveyors who evaluate whether or not the hospital is complying with Medicare's Conditions of Participation "for all services, areas and locations covered by the hospital's provider agreement under its CMS Certification Number (CCN)."73

7142 C.F.R. $\S 412.22$ (h) (2016).

7242 C.F.R. $\S 412.22$ (h)(2)(iii)(A) (2016).

73 Hospitals, CMS.Gov, http://www.cms.gov/Medicare/ProviderEnrollment-and-Certification/CertificationandComplianc/Hospitals.html [http://perma.cc/5CNH-NZDF] (last visited Feb. 28, 2016). 
The satellite hospital has a "home" facility. The satellite hospital may have the same CMS Certification number as its originating facility. ${ }^{74}$

\section{ADVANTAGES OF HoSPITALs-WithIN-HosPITALS}

\section{A. A Hospital-Within-A-Hospital Increases Physician Empowerment}

Clinical co-management is the means by which a hospital and an independent physician group (made up of physicians who are not employed by the hospital) form a relationship to

74 The Joint Commission describes the CCN as:

A hospital's CMS' Certification Number (CCN), is the hospital's identification number and is linked to its Medicare provider agreement. The CCN is used for CMS certification. Certain types of health care facilities, including hospitals, seeking to participate in the Medicare program are required not only to satisfactorily complete the Medicare enrollment application, but also to be certified as meeting the Medicare health and safety standards. The CCN is also used for submitting and reviewing the hospital's cost reports. The CCN number used to be called the "provider number," but with the advent of the statutorily mandated National Provider Identifier (NPI) number for claims processing, the CCN now plays a different role within the Medicare program.

Frequently Asked Questions about Accrediting Hospitals in Accordance with their CMS' Certification Number (CCN), THE JOINT CoMmission (Oct. 15, 2010), http://www.jointcommission.org/faqs_ccn/ [http://perma.cc/VEK6-5KBK]. 
work together to manage a particular area of a hospital..$^{75}$ Physicians struggle to maintain control of their independence as "mom and pop" shops are gobbled up by large hospital systems and they are forced to work for a large system. There are several types of relationships physician groups may form with hospitals. These include joint ventures, where the hospital and physician group form a limited liability company or other "joint venture business entity [ ] [that] then contracts with the hospital to provide defined management services and leadership." 76 The physician group then receives payment through "management fees paid by the hospital to the new entity[.]"77 Physicians may also create a physician entity that contracts with the hospital, where physicians are reimbursed for "management time and incentive for achieving certain goals."78 A hospital could "designate[] a few key administrators to sit on a council, or board, with select physicians" and work to "[d]efine[ service line or program goals and initiatives and helps to lead and coordinate hospital resources in achieving the objectives. Under the broad definition, hospital leadership and physicians are working collaboratively to achieve mutually beneficial objectives."79 None of these would compare to the freedom the physicians could have if they ran a specialty hospitalwithin-a-hospital.

75 Samuel G. Agnew \& Bryan J. Warren, When Does Clinical CoManagement Make Sense? 8 Considerations for Selecting the Model Right for Your Hospital, BeCKeR's HosP. REv. (Feb. 1, 2012), http://www.beckershospitalreview.com/hospital-physician-relationships/ when-does-clinical-co-management-make-sense-8-considerations-forselecting-the-model-right-for-your-hospital.html [http://perma.cc/RRR7ZAJZ].
${ }^{76} I d$.
$77 \mathrm{Id}$.
$78 I d$.
${ }^{79} I d$. 
There have been concerns related to physician referral patterns when physicians own health care facilities, specifically that they are "more likely than other physicians to refer well-insured patients to their facilities and route Medicaid patients to hospital outpatient clinics." 80 In the case of hospitals-within-hospitals, the physicians are not operating outpatient clinics. Rather, they have managerial control at the hospital for which they work. This set-up will not lead to excessive or inappropriate referrals as long as guidelines are in place and physicians and hospitals understand ethical limitations.

The hospital-within-a-hospital structure is highlighted as a way for physicians to regain control and be empowered to reduce medical errors. By

sell[ing] off operational units to physician specialists. In a sense, hospitals would [break apart] the hospital [into smaller pieces], vesting clinical and operational control to physician owners. Such a development follows a natural progression from the joint venture arrangements hospitals have engaged in with specialists in the outpatient area, and that are now seen on the inpatient side, most typically in the creation of "hospitals within" hospitals. ${ }^{81}$

80 Jon R. Gabel, et al., Where do I Send Thee? Does PhysicianOwnership Affect Referral Patterns to Ambulatory Surgery Centers?, 27 HEALTH AFF. w165 (2008), available at http://content.healthaffairs.org/ content/27/3/w165/suppl/DC2 [http://perma.cc/L98L-DYMU].

81 John D. Blum, Feng Shui and the Restructuring of the Hospital Corporation: A Call for Change in the Face of the Medical Error Epidemic, 14 HEAlTh MATRIX J.L. MED. 5 (2004). 
Any arrangements made by physicians and hospitals must not violate any health care fraud and abuse statutes. The analysis depends on the specific arrangement with the hospital and host hospital, and while the analysis is beyond the scope of this Note, it is necessary to draw attention to these two important statutes. The Stark Law prohibits physician "self-referrals." 82 Physicians are not permitted to make referrals for health services classified as "designated health services" ("DHS"). 83 The Stark Law also "prohibits the entity from presenting or causing to be presented claims to Medicare (or billing another individual, entity, or third party payer) for those referred services[" and "[e]stablishes a number of specific exceptions and grants the Secretary the authority to create regulatory exceptions for financial relationships that do not pose a risk of program or patient abuse." 84

Another ethical minefield that impacts the health care industry and hospitals is what is known as the federal AntiKickback Statute (“AKS"). 85 This statute calls for criminal penalties for making false statements and also for arranging for or offering illegal remunerations, meaning incentives like a bribe, to take certain actions. ${ }^{86}$ Illegal remunerations are an issue with the hospital-within-a-hospital because the structure could be impermissible if hospitals were involved in schemes to exclusively refer patients to the hospitalwithin-a-hospital.

82 Physician Self-Referral, CMS.Gov, http://www.cms.gov/Medicare/ Fraud-and-Abuse/PhysicianSelfReferral/index.html?redirect=/

physicianselfreferral/ [http://perma.cc/SL2F-65VJ] (last updated Jan. 5, 2015, 10:59 AM).

8342 U.S.C. $§ 1395 \mathrm{nn}(\mathrm{h})(6)$ (2016). DHS includes: clinical laboratory services; physical therapy services; occupational therapy services; radiology services, including magnetic resonance imaging, computerized axial tomography scans, and ultrasound services; radiation therapy services and supplies; durable medical equipment and supplies; parenteral and enteral nutrients, equipment, and supplies; prosthetics, orthotics, and prosthetic devices and supplies; home health services; outpatient prescription drugs; inpatient and outpatient hospital services. $I d$.

${ }^{84}$ Physician Self-Referral, supra note 82.

8542 U.S.C. $\S 1320 \mathrm{a}-7 \mathrm{~b}$ (2016).

${ }^{86} \mathrm{Id}$. 
The hospital-within-a-hospital and the host hospital will need to ensure that any arrangements are not in violation of these regulations.

\section{B. Reduction in Readmission Rates}

Readmission penalties from the Affordable Care Act make the hospital-within-the-hospital structure attractive as an incentive for hospitals to ensure readmission rates are low and for patients, who understandably do not wish to spend any more time than necessary in the hospital. Medicare payments will be reduced as a way to penalize hospitals for readmissions. Penalties have been doled out to three-fourths of hospitals that are included in the Hospital Readmissions Program and some have said that the pressure of penalties has encouraged hospitals to improve communications with other health care providers. 87

Excess readmissions are a focus of the Affordable Care Act, which established the Hospital Readmissions Reduction Program. The Secretary of HHS was tasked with establishing a program for hospitals to reduce readmission rates for certain conditions. ${ }^{88}$ The policy defines readmission for certain conditions and a calculation for them. ${ }^{89}$ CMS

87 Jordan Rau, Medicare Fines 2,610 Hospitals in Third Round of Readmission Penalties, KAISER HEALTH News (Oct. 2, 2014), http://kaiserhealthnews.org/news/medicare-readmissions-penalties2015/ [http://perma.cc/A2FG-GYLP].

8842 U.S.C. $\S 280 \mathrm{j}-3$ (2016).

89 Readmissions Reduction Program (HRRP), CMS.Gov, http:// www.cms.gov/Medicare/Medicare-Fee-for-Service-

Payment/AcuteInpatientPPS/Readmissions-Reduction-Program.html 
started adjusting payments to IPPS hospitals that are calculated to have excess readmissions on October 1, 2012.90 Excess readmissions are calculated by a specific formula through CMS. 91

[http://perma.cc/RJH2-SXXT] (last modified Feb. 4, 2016, 1:55 PM). The policy

[d] efined readmission as an admission to a subsection (d) hospital within 30 days of a discharge from the same or another subsection (d) hospital; Adopted readmission measures for the applicable conditions of acute myocardial infarction (AMI), heart failure (HF) and pneumonia (PN); Established a methodology to calculate the excess readmission ratio for each applicable condition, which is used, in part, to calculate the readmission payment adjustment. A hospital's excess readmission ratio [for AMI, $\mathrm{HF}$ and $\mathrm{PN}$ ] is a measure of a hospital's readmission performance compared to the national average for the hospital's set of patients with that applicable condition. Established a policy of using the risk adjustment methodology endorsed by the National Quality Forum (NQF) for the readmissions measures [for $\mathrm{AMI}, \mathrm{HF}$ and $\mathrm{PN}$ ] to calculate the excess readmission ratios, which includes adjustment for factors that are clinically relevant including certain patient demographic characteristics, comorbidities, and patient frailty. Established an applicable period of three years of discharge data and the use of a minimum of 25 cases to calculate a hospital's excess readmission ratio for each applicable condition. Id.

$90 \mathrm{Id}$.

91 See Julimes, Health Policy Brief: Medicare Hospital Readmissions Reduction Program, HeAlth AFF. (Nov. 12, 2013), available at http://healthaffairs.org/healthpolicybriefs/brief_pdfs/healthpolicybrief_1 02.pdf [httpshttp://perma.cc/P52M-R55R]. Excess readmissions are defined as follows:

[f]or purposes of the HRRP, excess readmissions are defined as those that exceed a hospital's "expected 
When a patient is discharged from a hospital, it is likely that some sort of follow-up or additional action has been advised, from taking medication on a certain schedule to asking the patient to be sure to check in with their primary care physician. A hospital-within-a-hospital may reduce transitional care issues between the host hospital and the specialty facility. This would benefit both the patient, who will not have to endure another hospital stay, as well as the host hospital, who will not be penalized for a readmission.

A 2014 report by Kaiser Health News, a nonprofit health policy news service, illuminates reasons that CMS is increasing its efforts to prevent readmissions. ${ }^{92}$ According to the report, "[n]early one in five fee-for-service Medicare patients returns to the hospital within 30 days of being discharged[.]" 93 A high readmission rate is sometimes an

readmission rate." A hospital's expected readmission rate for each of the HRRP conditions is the national mean readmission rate, risk-adjusted for the demographic characteristics (for example, age and sex) and severity of illness of the hospital's patients. The penalty is calculated using a complex formula based on the amount of Medicare payments received by the hospital for the excess readmissions. The penalties are collected from the hospitals through a percentage reduction in their base Medicare inpatient claims payments, up to a cap. The ACA set the penalty cap at 1 percent of aggregate IPPS base payments for the first year, 2 percent for the second year, and 3 percent for each year thereafter.

Id. at 3 .

92 Niall Brennan, Findings from Recent CMS Research on Medicare, CMS 28, http://kaiserhealthnews.files.wordpress.com/2014/10/ brennan.pdf [http://perma.cc/L6LZ-B774] (last visited Feb. 28, 2016).

${ }_{93} I d$. at 28. 
"indicator of poor quality care[.]"94 Additionally, of the $\$ 26$ billion that readmissions will cost Medicare each year, $\$ 17$ billion of the costs may be avoidable..$^{95}$

The hospital-within-a-hospital structure can be an effective tool to prevent excess readmissions, saving patients the hardship of enduring an additional stay at the hospital and saving Medicare, and ultimately the taxpayer, the costs related to readmissions. The hospital-within-a-hospital arrangement can alleviate issues with transitional care when a host hospital transfers a patient to the hospital-within-ahospital so that the individual can receive specialized services, which in turn could improve the readmission rates for the host hospital. Under the Affordable Care Act, hospitals will face reductions in their Medicare payments as a penalty for excessive readmissions. ${ }^{96}$ This means there is a financial incentive for hospitals to ensure patients receive appropriate transitional treatment.

\section{Specialty Hospitals Expand Access to Care}

There are financial restraints that prevent hospitals from opening up new children's hospitals in order to capture more business and serve additional populations. Construction costs often make new hospitals cost prohibitive. The hospital-within-a-hospital can be a means to create additional profit centers and improve the hospital's image or reputation. By arranging to lease space in a host hospital, the hospital-within-a-hospital can deliver care in an area where it previously did not make financial sense to set up an entire hospital to serve a smaller number of patients. This can expand access to a specific specialty hospital, like a

\footnotetext{
${ }_{94} I d$.

$95 \mathrm{Id}$.

${ }^{96} I d$. at 42 .
} 
children's hospital establishing a hospital-within-a-hospital in a rural host hospital.

In the past decade, there was an increase in specialty hospitals, ${ }^{97}$ which could lead to improvements in care because of the increased competition. Some groups are not in favor of an increase in specialty hospitals because general hospitals are unable to capitalize on these specialty cases the way a specialty hospital can because they cannot pick and choose their patients as easily. ${ }^{98}$ General hospitals may fail to capture revenue for procedures that would help them finance other low-profit cases. ${ }^{99}$

Hospitals across the country are developing centers geared towards specific health concerns and patients. ${ }^{100}$ This increase in specialty facilities demonstrates a "simple unifying theme behind this multifaceted array of institutions: specialty medicine." 101 Of the specialty endeavors, they "may be housed on separate floors within a hospital, be in separate administrative units (in- or outpatient) within a hospital, represent organizations within a hospital but with a distinct managerial structure ("hospital within a hospital"), be an entirely separate specialty hospital, or be physician owned." 102

Hospitals-within-hospitals are able to capitalize on the demand for specialty medicine. The hospital-within-ahospital arrangement is advantageous for certain hospitals

97 David Shactman, Specialty Hospitals, Ambulatory Surgery Centers, and General Hospitals: Charting a Wise Public Policy Course, 24 HEALTH AFF. 868, 868 (2005), available at http:// content.healthaffairs.org/content/24/3/868.full.pdf [http://perma.cc/ 89WH-CMU4].

98 Id.

${ }^{9} \mathrm{Id}$.

100 Robert A. Berenson et al., Specialty-Service Lines: Salvos in the New Medical Arms Race, 25 Health AFF. w337, w337-w339 (2006), available at http://content.healthaffairs.org/content/25/5/w337.full.pdf [http://perma.cc/K36F-EPN9].

101 Id. at w337.

102 Id. at w339. 
because they can "brand" their specialty and then offer their services at a remote location.

\section{A Unique Model of "Separateness"}

Although maternity units are not one of the care facilities excluded under the prospective payment system, a careful implementation of the "separateness" requirement could allow hospitals to use the hospital-within-a-hospital structure to facilitate delivery of certain types of health care services while protecting Catholic hospitals from violating deeply held convictions over permissible and impermissible health care services. Compelled to adhere to the Ethical and Religious Directives for Catholic Health Care Services, ("Ethical and Religious Directives"), moral guidelines created by the United States Conference of Catholic Bishops, Catholic hospitals usually have policies in place to refuse to provide certain services generally considered standard on moral grounds. ${ }^{103}$ Although individual providers practicing at a Catholic hospital may bend these rules at the hospital on an individual level (where they would likely be subject to discipline), or maintain separate offices to perform these services, Catholic hospitals typically do not offer reproductive services. Reproductive services usually include contraception, ${ }^{104}$ sterilization, abortion and infertility

103 See United States Conference of Catholic Bishops, Ethical AND Religious Directives for CATHOlic Health CARE SERVices (5th ed. 2009), available at http://www.usccb.org/issues-and-action/humanlife-and-dignity/health-care/upload/Ethical-Religious-Directives-

Catholic-Health-Care-Services-fifth-edition-2009.pdf [perma.cc/9PYG$5 \mathrm{NC} 5]$.

104 Lois Uttley \& Ronnie Pawelko, No Strings Attached: Public Funding of Religiously-Sponsored Hospitals in the United States (2002), available at http://www.mergerwatch.org/storage/pdf-files/ bp_no_strings_hilights.pdf [http://perma.cc/9J9G-EKEK]. This prohibition is of particular interest to some advocacy groups who fear that 
services, and counseling for safe sex. ${ }^{105}$ There may also be restrictions on a patient's end of life choices, as the medical team that handles end of life wishes may be required to follow the patient's wishes only to the extent that the wishes comport with the Ethical and Religious Directives. 106 Certain treatments derived from embryonic stem cell research, even those accepted in the wider medical community, may also be prohibited.107 This is because according to the Ethical and Religious Directives, the Catholic Church "cannot approve medical practices that undermine the biological, psychological, and moral bonds on which the strength of marriage and the family depends." 108

There was a sixteen percent increase in the number of Catholic hospitals from 2001 to 2011.109 In light of this increase, the hospital-within-a-hospital structure could be an opportunity to better serve the patient population of a geographic area where people only have convenient access to a Catholic hospital. ${ }^{110}$ For example, a Catholic health care system that hosts an independent, secular hospital-within-ahospital could provide treatment that the Ethical and Religious Directives do not allow. This would make additional healthcare services available to the local population and quell fears that the increase in Catholic hospital systems merging or acquiring secular hospitals will

the refusal to administer emergency contraception, even to victims of rape, will place an unfair and uncontrollable burden on the community served by the Catholic hospital.

105 Id.

106 Id.

${ }^{107} \mathrm{Id}$.

108 United States CONFEREnCE of CATHolic Bishops, supra note 103 , at 23 .

${ }^{109}$ Lois Uttley, Sheila Reynertson, Lorraine Kenny \& Louise Melling, Miscarriage of Medicine: The Growth of Catholic Hospitals and the Threat to Reproductive Health Care 4 (2013), available at http://www.aclu.org/sites/default/files/field_document/growth-of-catholichospitals-2013.pdf [http://perma.cc/2NR4-CRKU].

110 See id. 
lead to a reduction in available health care services for a community. This could also be a business opportunity for a hospital to specialize in operating hospitals-within-hospitals in Catholic hospitals. Of course, Catholic hospitals should not be compelled to participate in or endorse a practice that they find morally objectionable. There are many issues with Catholic hospital mergers that are outside the scope of this Note, but they include first amendment rights for medical staff that do not wish to compromise their moral beliefs by mandates that they provide certain types of treatments; issues with the providers who do not want a different kind of institutional conscience imposed on what they believe is their right to practice medicine as they see fit; and contentions that hospitals that treat Medicare and Medicaid patients, who may be elderly, disabled, and impoverished, should offer basic care.

A few Catholic hospitals have created models with similar "separateness" requirements, and one example is a hospital in Austin, Texas. This hospital used an arrangement that resembled the "hospital within a hospital" requirements, required by 42 C.F.R. $\S 412.22$, to allow a community "safety net" hospital to survive financially while not depriving members of the community of reproductive services like emergency contraception. 111 Seton, a Catholic hospital that the Daughters of Charity of St. Vincent De-Paul owned and managed, entered into a public-private partnership lease agreement with Brackenridge Hospital, owned and operated by the city of Austin, Texas, where Seton leased buildings from Brackenridge.112 Brackenridge, the city-owned hospital, was in serious financial trouble and was looking for

111 Barbra Mann Wall, Conflict and Compromise: Catholic and Public Hospital Partnerships, 18 NuRsing HIST. REV. 100 (2010), available at http://www.ncbi.nlm.nih.gov/pmc/articles/PMC2886734/pdf/nihms20484 0.pdf [http://perma.cc/Q7XK-4UCM].

112 Id. at 100. 
a lifeline to prevent its seemingly inevitable closure. ${ }^{113}$ Brackenridge Hospital played a crucial role in providing health services to community members of limited means, and its closure would have had a detrimental impact on this population. ${ }^{114}$ The fact that if Brackenridge Hospital was forced to shut its doors because of its financial situation, the poor would effectively be denied health care because the only other option was a for-profit hospital that would not provide the same amount of charity care led to the acceptance of this arrangement. ${ }^{115}$ This risk to the poor served as a powerful impetus to come to an arrangement that would allow Seton, as a Catholic entity, to serve the health care needs of the poor in the community while not compromising the moral principles to which Seton was ethically and morally compelled to adhere. ${ }^{116}$

Initially, the terms of the arrangement were organized so that Seton, the Catholic hospital, never performed and was never directly involved in care that was designated as morally objectionable by the Ethical and Religious Directives, but these reproductive services forbidden by the Ethical and Religious Directives were allowed to take place at Brackenridge.117 This type of compromise was in compliance with the Ethical and Religious Directives at the time due to a number of nuances in the arrangement,

\footnotetext{
113 Id.

${ }^{114} \mathrm{Id}$.

115 See generally id.

116 Id. at 101.

117 Id.
} 
including that Brackenridge was not deemed a Catholic hospital. ${ }^{118}$

When the Ethical and Religious Directives were later updated to forbid any type of working arrangement with a group that facilitated services the Catholic Church perceived as intrinsically evil, the hospitals had to adjust the arrangement, again to fulfill their duty to serve the needs of the poor in the community while still adhering to the highlyregarded Ethical and Religious Directives essential to their operation as a Catholic hospital ${ }^{119}$ Seton paid to create a solution that embodied similar characteristics to the hospital-within-a-hospital authorized by statute and allowed the hospital to continue to meet the medical needs of the poor community while maintaining "separateness." They included remodeling a floor of the hospital so that the secular, separately licensed facility could have "its own pharmacy, medical records area, nursing unit, housekeeping, and separate elevator." 120 This floor of the building was where all sterilization and contraceptive services, services the Ethical and Religious Directives does not support or allow on moral grounds, took place. ${ }^{121}$ The parties involved believed there were sufficient restrictions on contraceptives provided on an emergency basis that it was morally permissible for the Catholic hospital to allow the distribution of emergency contraceptives. ${ }^{122}$ Before transferring a woman in need of emergency contraceptives to the hospital-within-a-hospital "secular" floor, the woman had to be tested to ensure she was not ovulating at the time the medication was administered because otherwise the use of contraceptives would be morally impermissible. ${ }^{123}$ Although this arrangement might even surprise some devout Catholics as overly permissive, critics of the compromise said the restrictions interfered with and unnecessarily complicated the care female patients received. ${ }^{124}$

\footnotetext{
118 Id. at $105-106$.

119 Id. at $109-110$.

120 Id. at 111.

$121 \mathrm{Id}$. at 110 .

$122 \mathrm{Id}$.

${ }^{123} I d$. at 111.

${ }^{124}$ Id. at $110-11$.
} 
As the Ethical and Religious Directives tightened to forbid associations and compromises, this type of arrangement became more difficult, but if the Ethical and Religious Directives are ever modified to allow close relationships between secular and Catholic health care providers, the hospital-within-a-hospital structure is a novel framework to structure an arrangement through the separateness requirements, basic function, or the fifteen percent rule.

Burdett Care Center in Troy, New York is another example of a Catholic host hospital with a secular "hospitalwithin-a-hospital" that, like Brackenridge and Seton, embodies the structure of the hospital-within-a-hospital authorized by statute and shows that if separateness can be established to a level where a Catholic institution can share space with a hospital engaging in acts the Catholic institution believes is morally wrong, surely the statutory requirements are sufficient for operational separateness. ${ }^{125}$ Samaritan Hospital's parent corporation, Northeast Hospital, engaged in merger discussions with a Catholic hospital system, St. Peter's Health Care Services, regarding a merger with St. Mary's Hospital. ${ }^{126}$ Initially, there was alarm that the merger would restrict access to reproductive services. ${ }^{127}$ As a compromise, the new parent corporation of the two new partners was St. Peter's Health Partners, where

125 Lois Uttley, et al., Merging Catholic and Non-Sectarian Hospitals: New York State Models for Addressing the Ethical Challenges, 17 N.Y. ST. B.A. HEALTH L.J. 38, 41 (2012), available at http://static1.1.sqspcdn.com/static/f/816571/23042588/1372882137057/M odels+of+Catholic-secular+hospitals+mergers+in+NYS.pdf?token= 8wf9c2JeNXfIN8cT4A4olwNiuSo\%3D/ [http://perma.cc/3PXC-J6QQ].

${ }^{126} \mathrm{Id}$.

127 Id. 
“corporate 'members' St. Peter's and Seton Health retain[ed] their identities as Catholic facilities and member Northeast Health (including Samaritan Hospital) retain[ed] its identity as a non-sectarian health care system."128 This arrangement resulted in the creation of Burdett Care Center, a "hospitalwithin-a-hospital" on the second floor of Samaritan Hospital.129 The Burdett Care Center is a fifteen bed maternity hospital that "preserves services that can no longer be offered by Samaritan itself, under the terms of the merger: sterilization procedures, birth control and treatment of certain pregnancy emergencies." 130 In line with the separateness requirements, Samaritan provided a five million dollar trust to serve as a "financial buffer" and the Burdett Care Center established a different board and different staff than Samaritan. 131

It should be noted that while a specific hospital board and the bishop of a Catholic diocese who controls whether or not the agreement is allowed may agree to a similar arrangement, the strongly held call to respect and protect life means that many Catholics may still find these arrangements objectionable and consider them to be an unconscionable compromise. Additionally, changes to the Ethical and Religious Directives could bar this type of arrangement as well, and Catholic hospitals should not be compelled to arrangements that violate them. For instance, in November of 2014, the U.S. Conference of Catholic Bishops voted to update the Ethical and Religious Directives as they relate to the relationships of Catholic hospitals with secular hospitals. ${ }^{132}$ Specifically, this encompasses "matters such as

${ }^{128} I d$.

${ }^{129} \mathrm{Id}$.

${ }^{130} \mathrm{Id}$.

${ }^{131} I d$

132 Nina Martin, Catholic Bishops Vote to Revise Rules for Health Care Partnerships, ProPublica (Nov. 11, 2014, 10:17 AM), 
decisions of hospital administrators regarding possible cooperative arrangements with non-Catholic entities; distinctions between formal and material cooperation with evil; and moral decision-making as it applies to joint actions with partners, boards and other bodies." 133 There is speculation that the revisions will most likely make arrangements more difficult and less compromising. Regardless, the separateness and the benefits of the hospitalwithin-a-hospital system are a beneficial solution for the merging of Catholic and secular hospitals without compromising the types of services offered to women in the community. These secular-Catholic arrangements are examples of how two hospitals with different missions can coexist and serve the diverse needs of a community.

\section{PRoblems ASSOCIATED WITH A HOSPITAL- WITHIN-A-HOSPITAL}

\section{A. Overbilling}

Fear of hospitals overbilling or double billing for services is a common reason hospitals-within-hospitals are discouraged or disliked by those charged with protecting tax dollars and evaluating the expenditure of American dollars allocated to health care. Concerns that an LTCH hospital-

http://www.propublica.org/article/catholic-bishops-weigh-tighteningrules-for-health-care-partnerships [http://perma.cc/T244-37HZ].

133 Bishops to Vote on Proposal To Revise 'Ethical and Religious Directives for Catholic Health Care Services' at November Meeting, United States Conference of CATHOlic Bishops (Oct. 27, 2014), http://www.usccb.org/news/2014/14-171.cfm [http://perma.cc/7ZTPYGLL]. 
within-a-hospital can lead to overbilling of Medicare resulted in a moratorium for new LTCH hospitals. 134 In 2006, these concerns were best articulated by Herb B. Kuhn, then the director of CMS, who said at a hearing that nearly half of LTCHs were hospitals-within-hospitals, and over a ten-year period the number of LTCH hospitals-within-hospitals grew thirty-five percent. ${ }^{135}$ Kuhn contended that while CMS acknowledged that the arrangement can benefit patients and generate many operational efficiencies, "[colocation] also leads to patient shifting from one part of a hospital to another, resulting in two Medicare payments for what is essentially one episode of patient care." 136

A common perception of the LTCH, and the hospitalwithin-a-hospital in general, is that hospitals-withinhospitals create a mutually beneficial arrangement where the hospital-within-a-hospital is able to lease out an acute care hospital's extra space and empty beds and use the host hospital as a pipeline for patients. ${ }^{137}$ The argument is that the host hospital "gets a rent-paying tenant for its formerly unused space, and the LTCH saves the cost of building a freestanding facility and gets a steady provider of sick people."138

13442 C.F.R. $\S 412.23(\mathrm{e})(6)$ (2016). "[F]or the period beginning December 29, 2007 and ending December 28, 2012, [ ] a moratorium applies to the establishment and classification of a long-term care hospital [] or a long-term care hospital satellite facility ....” Id.

${ }_{135}$ Long Term Acute Care Hospitals: Hearing before the Subcomm. on Health of the Comm. on Ways and Means, 109'th Cong. 2 (2006) (statement of Director Herb B. Kuhn, Center for Medicare Management, Ctrs. for Medicare and Medicaid Svcs., U.S. Dept. of Health and Human Svcs), available at http://www.gpo.gov/fdsys/pkg/CHRG-109hhrg30439/ html/CHRG-109hhrg30439.htm [http://perma.cc/74EP-NJ7F].

${ }_{136} \mathrm{Id}$.

137 Josh Levin, The Other Katrina Hospital Mystery, SLATE (Sept. 4, 2009, 7:03 AM), http://www.slate.com/articles/news_and_politics/ prescriptions/2009/09/the_other_katrina_hospital_mystery.single.html [http://perma.cc/9XR5-PXD6].

138 Id. 
In agreement, concerns have been articulated that "because the relationship between long-term care [hospitals-withinhospitals] and their host hospitals is necessarily close, the two institutions could easily work together to circumvent the cost control intent of Medicare's PPS payments." 139

This concern has also been expressed in case law, where there are concerns that the hospital-within-a-hospital arrangement would tempt the acute care host hospital to abuse the system. For example,

[a]n acute care hospital that consistently discharges a higher cost patient to a postacute care setting for the purpose of lowering its costs undercuts the foundation of the IPPS DRG system, which is based on averages. In this circumstance, the hospital would recoup larger payments from the Medicare system than is intended under the DRG system because the course of acute treatment has not been completed. At the same time, the patient, still under active treatment for an acute illness, will be admitted to a LTCH, thereby generating a second admission and Medicare payment that would not have taken place but for the fact of $\mathrm{co}^{-}$ location. ${ }^{140}$

139 Susan E. Cancelosi, Fighting Medicare Fraud in Long-Term Care Hospitals-within-Hospitals: OIG Documents Ongoing Failures while Industry Groups Complain 2 (unpublished), available at http://www.law.uh.edu/healthlaw/perspectives/(SC)LTCHWHrev.pdf [http://perma.cc/38VP-K455].

140 Select Specialty Hosp., 820 F. Supp. 2d 13, at 18 (quoting 69 Fed. Reg. 28196, 28325 (May 18, 2004)). "Since 1983, under 42 U.S.C. $\S$ 
In this scenario, Medicare pays more than the necessary amount to the host hospital for the same patient. A letter from the Office of the Inspector General indicated that many LTCHs have not notified Medicare of their co-located status, which will lead to overpayment by Medicare. ${ }^{141}$ A hospitalwithin-a-hospital structure that benefits from the payment system could be bad for taxpayers and may signal that LTCHs need to scrutinize their own adherence to the standards set by Medicare. However, careful adherence to permissible billing practices and clear guidelines from Medicare will help prevent overbilling.

\section{B. "Separateness" as an Impediment to Disaster Preparedness}

Beyond payment issues with Medicare that give rise to concerns about the hospital-within-a-hospital structure, another significant barrier that the hospital-within-ahospital might face is the effectiveness of their plan of action in the event of an emergency. Sharing a physical location while the leadership and staff are independent can lead to difficulties.

The pressure of an impending emergency situation can bring internal hospital system failures to the surface, sometimes in tragic ways. The events that took place at a hospital in New Orleans when the host hospital and hospital-

$1395 w w(d)$ the Medicare program has paid for an acute care hospital's operating costs in furnishing inpatient services to Medicare beneficiaries under a prospective payment system ("Inpatient PPS" or "IPPS"), in which payment is made at a predetermined, specific rate for each discharge." Id. at 17.

${ }^{141}$ Daniel Levinson, Vulnerabilities in Medicare's Interrupted-Stay Policy for Long-Term Care Hospitals, Department Health \& Hum. SERVICES 19 (June 2014), http://oig.hhs.gov/oei/reports/oei-04-1200490.pdf [http://perma.cc/489R-DLAS]. 
within-a-hospital, failed to work together in a time of severe crisis brought on by Hurricane Katrina and her aftermath, to illustrate how deadly serious it is for the host hospital and the hospital-within-a-hospital to maintain separate control but also to be aware of emergency plans and coordinate in a permissible manner.

In this case, the hospital-within-a-hospital was an LTCH where patients were extremely ill and in need of constant lifesustaining treatment, that makes any evacuation more dangerous to the health and safety of the patient and more complicated on a logistical level. When Hurricane Katrina struck New Orleans in late August of 2005, chaos ensued. On Sunday, August 28, 2005, Hurricane Katrina was a Category Five storm. ${ }^{142}$ Hospitals should have been well-prepared for the destruction that would occur based on warnings from the National Oceanic and Atmospheric Administration, who warned the public that

[m] ost of the area will be uninhabitable for weeks ... perhaps longer. At least one half of well constructed homes will have roof and wall failure.... The majority of industrial buildings will become non functional ... . Airborne debris will be widespread and may include heavy items such as household appliances and even light vehicles. . . Persons, pets, and livestock exposed to the winds will face certain death if struck. Power outages will last for weeks. . .

\footnotetext{
14214 Days $A$ Timeline, Frontline (Nov. 25, 2005), http://www.pbs.org/wgbh/pages/frontline/storm/etc/cron.html [http:// perma.cc/LJY6-K54Y].
} 
water shortages will make human suffering incredible by modern standards. ${ }^{143}$

The mayor of New Orleans at the time, Mayor Ray Nagin, initiated a mandatory evacuation that resulted in 30,000 people placed in emergency shelter at the Superdome. ${ }^{144}$ The Superdome was only stocked with enough emergency provisions to feed half the number of people there for three days. ${ }^{145}$ Due to the severity of the storm, emergency workers were unable to respond to people in need of help. ${ }^{146}$ Once the eye of the storm passed through the city, officials were prepared to begin clean-up efforts. ${ }^{147}$ However, the city was unprepared for the still-rising floodwaters that resulted after the levees that protect the city from flooding broke. ${ }^{148} \mathrm{By}$ Wednesday, August 31, officials estimated that eighty percent of the city was under water, there was rampant looting throughout the city by both opportunistic and desperate individuals, and the focus shifted to evacuating the individuals in the Superdome. ${ }^{149}$ Lack of coordination between then-governor of Louisiana, Kathleen Blanco, Federal Emergency Management Agency ("FEMA") director Michael Brown, and New Orleans Mayor Ray Nagin was blamed for the absence of an appropriate and efficient response to the emergency. ${ }^{150}$ Frustrated by what he saw as an inadequate response, Mayor Nagin inflamed the public after he spoke on a radio show, with disparaging pronouncements on the action officials had taken. ${ }^{151}$ Michael

$$
\begin{aligned}
& { }^{143} \mathrm{Id} . \\
& { }^{144} \mathrm{Id} . \\
& { }^{145} \mathrm{Id} . \\
& { }^{146} \mathrm{Id} . \\
& { }^{147} \mathrm{Id} . \\
& { }^{148} \mathrm{Id} . \\
& { }^{149} \mathrm{Id} . \\
& { }_{150} \mathrm{Id} \\
& { }_{151} \mathrm{Id} .
\end{aligned}
$$


Brown, then-FEMA director, admitted to misleading the public in order to maintain calm, despite the fact that the FEMA Situation Update reported that the situation had escalated to the point where, shockingly,

[1]aw and order all but broke down in New Orleans over the past few days. Storm refugees reported being raped, shot and robbed, gangs of teenagers hijacked boats meant to rescue them, and frustrated hurricane victims menaced outmanned law officers. Police Chief Eddie Compass admitted even his own officers had taken food and water from stores. Officers were walking off the job by the dozens. ... ${ }^{152}$

Reflecting the significant coordination problems that federal, state and local officials encountered during Hurricane Katrina, LifeCare, a hospital-within-a-hospital, experienced significant difficulties coordinating an evacuation plan with its host hospital that arguably led to patients being euthanized. ${ }^{153}$ A contributing factor to the difficulties of the evacuation of this hospital was the lack of understanding about how the two separate hospitals should interact. ${ }^{154}$ LifeCare leased the seventh floor at Memorial Medical Center in New Orleans, Louisiana. ${ }^{155}$ LifeCare,

\footnotetext{
${ }^{152} I d$.

${ }^{153}$ Sheri Fink, The Deadly Choices at Memorial, N.Y. TIMES (Aug. 25, http://www.nytimes.com/2009/08/30/magazine/30doctors.html?pagewant ed=all\&_r=0 [http://perma.cc/YS7M-3FRQ] .

${ }_{154} \mathrm{Id}$.

$155 \mathrm{Id}$.
} 2009), 
which adhered to the separateness tenant required of LTCHs in the sense that it credentialed its own staff, worked to keep patients who were elderly or incredibly ill alive with technology that some doctors at Memorial believed was too drastic for the patient and a waste of resources. 156 This attitude that patients on the LifeCare floor were "chronically deathbound" contributed to what some experts say was the euthanasia of patients that hospital workers considered too sick to move. ${ }^{157}$

LifeCare was not invited to the discussions that happened among hospital staff over their plan of evacuation when the situation took a turn for the worse. ${ }^{158}$ LifeCare had an incident commander who was responsible for organizing the evacuation of the LifeCare patients and had requested that the LifeCare patients be included in Memorial's evacuation plans. ${ }^{159}$ The incident commander was told that Memorial would ask their corporate owner, Tenet, for permission to include them in Memorial's evacuation plans. ${ }^{160}$ Tenet claims that LifeCare workers rejected an offer of evacuation assistance. ${ }^{161}$ Regardless of which side is right, it is clear there was a breakdown in communication among staff and multiple layers of leadership.

In response to the Fink article, Ellen B. Griffith, a spokesperson for CMS, said that because it was not clear there was a LifeCare physician available on the LifeCare floor, it "raises questions about whether the LifeCare facility really was a separately certified hospital from Memorial Medical Center or was actually functioning as a unit of Memorial."162 This indicates that disregarding the separateness rule can lead to the hospital-within-a-hospital being taken advantage of by host hospital doctors, in addition to contributing to a dangerous silo where communication does not flow freely.

156 Id.

${ }^{157} \mathrm{Id}$.

${ }^{158} I d$.

159 Id.

${ }_{160} I d$

${ }^{161} I d$.

${ }^{162}$ Levin, supra note 137. 
Although the issues at Memorial demonstrate the devastating effects of a hospital-within-a-hospital that lacks structures and protocols for their own patients and a lack of understanding of how the hospital-within-a-hospital and the host hospital need to interact, there are examples of hospitals-within-hospitals that have successfully managed emergency situations. An example of a hospital-within-ahospital that successfully and smoothly handled an emergency evacuation is Triumph Hospital. Triumph Hospital is a long term acute care hospital-within-a-hospital whose host at the time was MeritCare hospital. ${ }^{163}$ In the face of dangerous floods as the nearby Red River rose, the health care workers were able to act to prevent threats to patient safety. ${ }^{164}$

When the "evacuation trigger was pulled at MeritCare, patients had been ready to roll for hours, [with] baggies of medicines at their bedsides, checklists on their doors, and bar-coded triage bracelets on their wrists whose colors indicated the type of transport required." 165 The chief clinical officer of Triumph said she felt like she was "overly prepared," a sentiment that the officials at Memorial likely did not experience. ${ }^{166}$ The health care providers said that several factors contributed to their success: "flexibility, days

163 Sheri Fink, Disaster Preparedness Pays off in North Dakota, ProPublica (Mar. 31, 2009, 11:52 AM), http://www.propublica.org/ article/disaster-preparedness-pays-off-in-North-Dakota-20090331

[http://perma.cc/8LYJ-2YGJ].

${ }_{164} \mathrm{Id}$.

165 Id.

${ }_{166} I d$. 
of advance planning, and strong collaboration between health facilities and local, state and federal government."167

Other external risks besides natural disasters can present challenges to hospitals-within-hospitals. Another risk to both the host hospital and the hospital-within-a-hospital is infection control. As evidenced by the 2014 Ebola outbreak, infectious diseases can severely impact the health of the community, as well as the public's perception of community safety. 168 Appropriate protocols need to be in place to prevent transferring infections from one institution to another.

Although the events at Memorial Care Center in New Orleans show that a poorly organized plan of action in the face of a disaster can have devastating consequences for patients of a hospital-within-a-hospital, this is something that hospitals-within-hospitals should be able to overcome with careful planning. Hospitals-within-hospitals should be able to work with their host hospital in a way that does not endanger the safety of patients in emergency situations but also avoiding impermissible acts of control by one hospital over another. During emergencies, hospitals in a community typically collaborate with each other, even if they are bitter rivals every other day of the year. In the event of a catastrophe, hospitals need to be able to handle the "surge" that occurs during emergencies and need "the ability to respond to mass casualty events and adequately care for a sudden influx of patients with common or unusual medical needs." 169

${ }^{167} I d$.

168 See 2014 Ebola Outbreak in West Africa, CENTERS FOR DisEASE CONTROL \& PREVENTION, http://www.cdc.gov/vhf/ebola/outbreaks/2014west-africa/ [http://perma.cc/P7WY-SAVX] (last visited Feb. 28, 2016).

${ }^{169}$ Public Health Emergency Preparedness and Response, U.S. Gov'T ACCOUNTABILITY OFF., http://www.gao.gov/key_issues/ public_health_emergency_preparedness_response/issue_summary [http://perma.cc/BH3V-DKDC] (last visited Feb. 28, 2016). 
A community-wide disaster preparedness committee with all hospital stakeholders represented is an innovative solution to the issue. In Indiana, hospitals participate in a public-private coalition called Managed Emergency Surge for Healthcare Coalition, or MESH.170 MESH "creates a forum for healthcare organizations to collaboratively address issues ranging from operational readiness to reimbursement following a catastrophic disaster." 171 MESH "brings the pieces of the emergency healthcare puzzle together."172 The MESH Coalition provides a forum for hospitals to distribute resources as needed and creates centralized "preparedness functions." 173 Currently, MESH is comprised of both public and private members and it includes the Marion County Public Health Department and other hospitals. ${ }^{174}$ This type of community-wide collaboration would be ideal because it would help all health care providers in the event of an emergency. The hospital-within-a-hospital should not be considered under the "control" of its host hospital because it is simply a participating member of a community-wide disaster plan. An organization like MESH would alleviate confusion and would serve to prevent catastrophes like the situation that happened with Memorial and LifeCare. Disaster preparedness concerns should not bar the formation of a hospital-within-a-hospital; rather it is another factor to take into consideration when forming a hospital-within-ahospital.

170 See MESH COALITION, http://www.meshcoalition.org [http:// perma.cc/H5CU-DSMD] (last visited Jan. 29, 2016).

171 MARION COUNTY ARES, http://www.mcinares.org/mesh-coalition [http://perma.cc/5R2W-8SGE] (last visited Jan. 29, 2016).

172 MESH COALITION, supra note 170.

173 Justin Mast, Fostering Community: How One Indiana Community Meshed its Resources to Improve Preparedness, Trust for Am.'s HEALTH (June 4, 2015), http://healthyamericans.org/health-issues/ prevention_story/mesh-community-resilience/ [http://perma.cc/96G5CMTE]; see MESH COALITION, supra note 170.

174 MESH COALITION, supra note 170. 


\section{CONCLUSION}

The hospital-within-a-hospital is a structure that provides opportunities for the host hospital that benefits both hospitals involved and the patients in the geographic area. The hospital-within-a-hospital benefits outweigh the operational difficulties in ensuring adherence to the requirements of the statute, especially the more complicated "separateness" requirement, in addition to concerns about violating the Stark Law or AKS. Reduced readmissions through better transitional care benefits both the patient who must endure the difficulty of additional time in the hospital and the hospital that will suffer from financial penalties for excessive readmissions. Reduced readmission allows the host hospital to avoid readmission penalties from Medicare. The hospital-within-a-hospital is a means for host hospitals to achieve both financial and quality goals, despite payment issues and operational difficulties that arise due to CMS constraints on the hospital-within-a-hospital. Physicians could use the hospital-within-a-hospital structure to maintain their power and autonomy during an era of physician practices being purchased by large health systems.

Catholic hospitals, which are growing in number as regulator pressure drives increases in hospital consolidations and mergers, could authorize an arrangement with a hospital-within-a hospital to preserve certain patient services that would otherwise be limited. This could also be effective for other religious hospitals that are guided by moral principles that forbid offering certain treatments. The benefits to patients in terms of convenience and cost efficiency outweigh any potential risks that a hospitalwithin-a-hospital will take advantage of the payment systems and churn bills.

Disaster preparedness arrangements, like MESH, will alleviate concerns that host hospitals will cross into dangerous territory of making life or death decisions for the hospital-within-a-hospital's patients. MESH would also alleviate issues of impermissible lack of separation if the host hospital and the hospital-within-a-hospital need to work together to coordinate their emergency response plans.

Overall, the separateness requirements of the host hospital and the hospital-within-a-hospital ensure that this 
system will not result in unethical arrangements. The chief medical officer of the host hospital is separate from the hospital-within-a-hospital as well as the medical staff. The CEO is not permitted to be employed by the hospital-withinthe-hospital. These safeguards should allow for the creation of more of these entities to better serve patients and offer more diverse services in areas that need them the most. 